\title{
Hepatocellular carcinoma in alcoholic and non-alcoholic fatty liver disease-one of a kind or two different enemies?
}

\author{
Christine Pocha, Chencheng Xie \\ ${ }^{1}$ Avera McKennnan Hospital and University Medical Center, Sanford School of Medicine, University of South Dakota, Sioux Falls, SD, USA; \\ ${ }^{2}$ Department of Gastroenterology and Hepatology, Thomas Jefferson University, Philadelphia, PA, USA \\ Contributions: (I) Conception and design: All authors; (II) Administrative support: None; (III) Provision of study materials or patients: None; (IV) \\ Collection and assembly of data: All authors; (V) Data analysis and interpretation: All authors; (VI) Manuscript writing: All authors; (VII) Final \\ approval of manuscript: All authors. \\ Correspondence to: Christine Pocha. Avera McKennnan Hospital and University Medical Center, Sanford School of Medicine, University of South \\ Dakota, 1315 S. Cliff Ave, Suite 1200, Sioux Falls, SD 57105, USA. Email: Christine.pocha@avera.org; Christine.pocha@usd.edu.
}

\begin{abstract}
Hepatocellular cancer (HCC) is a cancer with an overall poor prognosis and an alarming globally rising incidence. While viral etiology of chronic liver disease and HCC is down-trending, alcohol and excess calorie intake have emerged as major culprits. Alcohol related liver disease (ALD) and non-alcoholic fatty liver disease (NAFLD) share similar pathogenetic mechanism of hepatic injury and in promoting development of HCC; yet some genetic and epigenetic features are distinct and may promise clinical utility. Population based intervention are urgently needed to reduce alcohol use and improve metabolic factors such as obesity and diabetes. The goal is to identify at-risk patients, to link these patients to care and to provide effective management of chronic liver disease and HCC. This review focuses on the epidemiology, pathophysiology including genetic and epigenetic altercation as well as clinical aspects of ALD and NAFLD associated HCC.
\end{abstract}

Keywords: Alcoholic liver disease (ALD); non-alcoholic fatty liver disease (NAFLD); hepatocellular cancer (HCC)

Received: 14 June 2019; Accepted: 22 August 2019; Published: 09 October 2019.

doi: $10.21037 / \operatorname{tgh} .2019 .09 .01$

View this article at: http://dx.doi.org/10.21037/tgh.2019.09.01

\section{Introduction}

Liver cancer is the fifth most common cancer in men and ninth most common in women with hepatocellular cancer (HCC) accounting for more than $90 \%$ of cases (1). Ageadjusted incidence of HCC rose from 1.5 to 4.9 per 100,000 individuals over the past 30 years alone in the US (2). Overall, HCC has a poor prognosis with a high mortality. In 2012 , there were approximately 782,000 new cases and 746,000 deaths from liver cancer worldwide (1). The BRIDGE study accounted hepatitis C infection (HCV) for the majority of cases in North America, Europe and Japan, and hepatitis B (HBV) in China and South Korea (3). HCC prevalence has been alarmingly rising with an increased incidence of 75\% between 1990 and 2015 (4); yet, the overall picture is changing. While rates of viral hepatitis related HCC are globally down-trending, metabolicrelated HCC has increased sharply across continents in line with increasing rates of metabolic syndrome (MetS), obesity, and insulin resistance (IR) (1,5). A similar trend is seen with alcohol-related liver disease (ALD)-related HCC (ALDHCC) $(3,4,6,7)$.

ALD and non-alcoholic fatty liver disease (NAFLD) share similar histologic features particularly steatosis, suggesting similar pathogenetic mechanisms of hepatic inflammation and injury. Alcohol consumption and excessive dietary caloric intake potentiate the risk of liver injury. Naveau et al. showed that excess weight for at least 10 years is an independent risk factor for cirrhosis, acute alcoholic hepatitis and steatosis (8). With rising incidence and prevalence of NAFLD and ALD, potentially compensating for the down-trending chronic liver disease rates from other 
causes globally, the effect of ALDHCC and NAFLDHCC is of special interest.

Patients with nonalcoholic steatohepatitis (NASH), the aggressive form of NAFLD have a greater risk to develop HCC $(3,9)$; and HCC cases have been found in noncirrhotic patients, potentially interfering with early detection of small, potentially curable tumors and therefore leading to morbidity and mortality in patients with otherwise mild fibrosis and preserved liver function.

According to the HEPAHEALTH Project Report, globally, in 2015, the second leading etiology of underlying liver disease was alcohol use (10). The 2015 Global Burden of Disease study estimated an incidence of 854,000 liver cancer cases and 810,000 deaths globally with alcohol accounting for $30 \%$ of all liver cancer cases (4).

Furthermore, both ALD and NAFLD interact with other liver etiologies and deteriorate the disease processes $(11,12)$. Chronic, excessive alcohol use synergistically promotes liver disease and HCC risk in NAFLD, HBV, and HCV patients $(13,14)$. Vice versa, obesity increases the vulnerability of the liver to the toxic effect of alcohol and is an independent predictor for HCC in patients with ALD (15).

In this review, we summarize current evidence regarding epidemiology, tumorigenesis, clinical pathogenesis, and management of HCC that develops in the context of both ALD and NAFLD.

\section{Epidemiology of NAFLD-related HCC (NAFLDHCC)}

With NAFLD currently emerging as a global morbidity it is not surprising that NAFLDHCC is on the rise (Table 1) NAFLD contributes to a large number of HCC and NAFLDHCC has increased over the past decades (3,16-21). Across continents large population-based studies have reported proportions of NAFLDHCC between $14.1 \%$ (19) and $21.5 \%$ (17), combined with an annual increase of NAFLDHCC by $9 \%$ in the US (19), greater than 10-fold increase between 2000 and 2010 in the UK (17); as well as an increase from $3.8 \%$ during the 2001-2005 period to $12.2 \%$ during the $2006-2010$ period in Korea (16). NASH only accounts for a small portion of NAFLD; yet it can be attributed to a significant proportion of HCC. Prevalence of NASHHCC shows geographic variations with a range of $10-12 \%$ in North America and Europe and 1-6\% in Asia (3). It seems to be the most rapidly growing cause of HCC (19). The proportion of NASHHCC increased from $0 \%$ in 2002 to $6.0 \%$ in 2012 in a cohort of 10,062 HCC patients who underwent liver transplantation (18) and from $2.1 \%$ in 2002 to $17.9 \%$ in 2017 in 28,935 HCC patients using the Scientific Registry of Transplant Recipients (SRTR) data (21).

Overall, incidence of NAFLDHCC seems low (6,14,22-32). A recent meta-analysis of 86 studies from 22 countries with a population of $8,515,431$ reported a NAFLDHCC incidence of 0.44 (0.29-0.66) per 1,000 personyears (29). An annual incidence of NAFLDHCC of $0.043 \%$ was reported in another large scale study (24) while a small-scale Belgian study showed an accumulative risks of NAFLDHCC of $3.1 \%$ and a 10 -year cumulative incidence rate of $23.7 \%$ (30). Another small-scale study from Brazil, reported a 10 -year accumulated NAFLDHCC rate of 9\% (31). Differences between these study results are likely due to the different proportions of NASH, fibrosis, or cirrhosis patients in the sample pool. The risk to develop HCC dramatically increases in the later stages of the NAFLD spectrum. Amarapurkar et al. (25) reported a $0.46 \%$ annual rate of cirrhotic NASHHCC; two Japanese studies reported a 5 -year cumulative incidence of HCC of $7.6 \%$ in NASH with advanced fibrosis which increased to $11.3 \%$ in NASH with cirrhosis $(22,23)$. Nonetheless, compared with viral hepatitis, NAFLD is a low-risk factor for HCC. Multiple studies consistently demonstrated that the incidence of HCC in the context of NASH cirrhosis is much lower than with $\mathrm{HCV}$, which has a reporetd annual HCC incidence of $3.6-4.0 \%$ and a 5 -year cumulative incidence of $11.3 \%(14,23,25)$. However, NAFLDHCC incidence has increased from $0.0263 \%$ in 2002 to $0.0514 \%$ in 2012 (6); thus among all the risk factors that might induce HCC, the contribution of NAFLD will rise the most noticeable.

\section{Epidemiology of ALD-related HCC (ALDHCC)}

As in NAFLD the risk of developing HCC is higher at a later stage of ALD (33). ALD has a great disease burden and alcohol accounts for $30 \%$ of liver cancer deaths globally (4). Table 2 summarizes prevalence and incidence of ALDHCC. In the BRIDGE study, ALD contributed to a larger portion of HCC cases in North America (21\%) and Europe (37\%) compared to East Asia (4-13\%) (3). Three large-scale retrospective US cohort studies have shown consistent results. Younossi et al. utilized SEER registries reporting a proportion of ALDHCC of $16.4 \%$ over 5 years from 2004-2009 (19). Another retrospective cohort study using 15 years of data from the SRTR including 28,935 HCC patients on the liver transplant (LT) waitlist found that 
Table 1 Prevalence and Incidence of NAFLDHCC

\begin{tabular}{|c|c|c|c|c|c|}
\hline Study & Design & Population & Study period & Diagnostic method & Findings \\
\hline $\begin{array}{l}\text { Dyson et al., } \\
2014(17)\end{array}$ & $\begin{array}{l}\text { Retrospective } \\
\text { cohort }\end{array}$ & UK, 632 patients with HCC & 2000-2010 & Imaging or biopsy & $\begin{array}{l}\text { Proportion of NAFLDHCC: } \\
21.5 \%(136 / 632) \text { in } 2010 \text {, } \\
\text { proportion of NAFLD HCC death: } \\
34.8 \%(35 / 114) \text { by } 2010 \\
\text { Proportion of NAFLD HCC with } \\
10 \text {-fold increase over the } \\
10 \text { years }\end{array}$ \\
\hline $\begin{array}{l}\text { Wong et al., } \\
2014(18)\end{array}$ & $\begin{array}{l}\text { Retrospective } \\
\text { cohort }\end{array}$ & $\begin{array}{l}\text { US, UNOS registry; } \\
61,868 \text { adults with LT } \\
\text { including 10,061 with HCC }\end{array}$ & 2002-2012 & $\begin{array}{l}\text { NASH: not specified; } \\
\text { modified NASH } \\
\text { category: previous } \\
\text { diagnosis of NASH, } \\
\text { Cryptogenic cirrhosis, } \\
\text { unknown cirrhosis with } \\
\text { obesity }\end{array}$ & $\begin{array}{l}\text { Proportion of NASHHCC } \\
\text { increased: 0\% [2002] vs. } \\
4.0 \% \text { [2007] vs. 6.0\% [2012]; } \\
\text { modified NASH category criteria: } \\
\text { proportion of NASHHCC: } 8.3 \% \\
\text { [2002] vs. 10.3\% [2007] vs. } \\
13.5 \% \text { [2012] }\end{array}$ \\
\hline $\begin{array}{l}\text { Younossi et al., } \\
2015 \text { (19) }\end{array}$ & $\begin{array}{l}\text { Retrospective } \\
\text { cohort }\end{array}$ & $\begin{array}{l}\text { US, SEER registries, } \\
\text { 4,929 HCC cases }\end{array}$ & 2004-2009 & $\begin{array}{l}\text { ICD-9 NAFLD or } \\
\text { cryptogenic liver } \\
\text { disease, cirrhosis with } \\
\text { diabetes/obesity }\end{array}$ & $\begin{array}{l}\text { Proportion of NAFLDHCC: } \\
14.1 \% ; 9 \% \text { annual increase of } \\
\text { NAFLDHCC; among HCC patient } \\
\text { who received LT only } 5 \% \text { were } \\
\text { NAFLDHCC }\end{array}$ \\
\hline $\begin{array}{l}\text { Park et al., } \\
2015 \text { (3) }\end{array}$ & $\begin{array}{l}\text { Retrospective } \\
\text { cohort }\end{array}$ & $\begin{array}{l}\text { BRIDGE, } 14 \text { countries, } \\
42 \text { sites, } 18,031 \text { HCC } \\
\text { patients }\end{array}$ & 2005-2012 & Not specified & $\begin{array}{l}\text { Proportion of NASHHCC: North } \\
\text { America 12\%, Europe 10\%, } \\
\text { China 5\%, South Korea 6\%, } \\
\text { Japan } 2 \%\end{array}$ \\
\hline $\begin{array}{l}\text { Hashimoto } \\
\text { et al., } 2009 \text { (22) }\end{array}$ & $\begin{array}{l}\text { Prospective } \\
\text { cohort }\end{array}$ & Japan, 137 NASH patients & 1990-2007 & Liver biopsy & $\begin{array}{l}\text { 5-year cumulative incidence } \\
\text { of HCC: } 7.6 \% \text { in NASH with } \\
\text { advanced fibrosis }\end{array}$ \\
\hline $\begin{array}{l}\text { Yatsuji et al., } \\
2009(23)\end{array}$ & $\begin{array}{l}\text { Prospective } \\
\text { cohort }\end{array}$ & $\begin{array}{l}\text { Japan, } 68 \text { patients with } \\
\text { cirrhotic NASH }\end{array}$ & 1990-2006 & Liver biopsy & $\begin{array}{l}\text { 5-year cumulative incidence of } \\
\text { HCC: } 11.3 \% \text { in NASH cirrhosis }\end{array}$ \\
\hline $\begin{array}{l}\text { Ascha et al., } \\
2010(14)\end{array}$ & $\begin{array}{l}\text { Prospective } \\
\text { cohort }\end{array}$ & $\begin{array}{l}\text { US, } 195 \\
\text { NASH cirrhosis }\end{array}$ & 2003-2007 & Not specified & $\begin{array}{l}\text { Annual incidence of HCC: } 2.6 \% \\
\text { in cirrhotic NASH }\end{array}$ \\
\hline $\begin{array}{l}\text { Kawamura } \\
\text { et al., } 2012 \text { (24) }\end{array}$ & $\begin{array}{l}\text { Retrospective } \\
\text { cohort }\end{array}$ & $\begin{array}{l}\text { Japan, } 6,508 \text { patients with } \\
\text { NAFLD }\end{array}$ & 1997-2010 & $\begin{array}{l}\text { Imaging } \\
\text { (ultrasonography) }\end{array}$ & $\begin{array}{l}\text { Annual incidence of NAFLDHCC: } \\
0.043 \% \text {. Cumulative rates of } \\
\text { NAFLDHCC were } 0.02 \% \text { (year } 4 \text { ), } \\
0.19 \% \text { (year } 8), 0.51 \% \text { (year 12) }\end{array}$ \\
\hline
\end{tabular}

Table 1 (continued) 
Table 1 (continued)

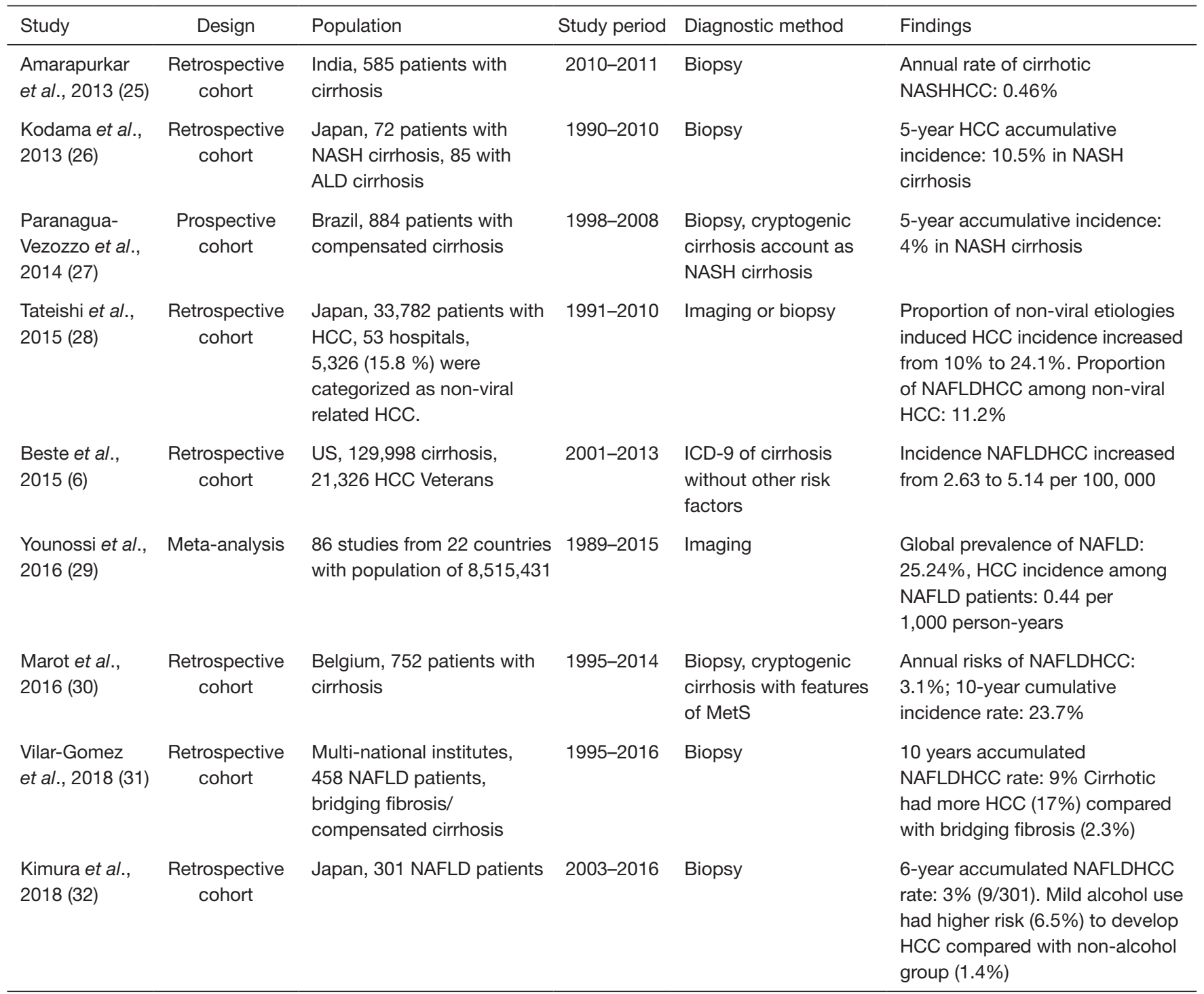

ALDHCC increased from $8.3 \%$ in 2002 to $14.2 \%$ in 2017 (21). A Veterans' Affairs (VA) study on 129,998 cirrhosis patients including 21,326 with HCC found that $11 \%$ were ALD related (6). In the UK, the proportion of ALDHCC is much higher, accounting for $28.2 \%$ by 2010 (17).

As in NAFLD, overall, the annual incidence of HCC in ALD patients is low. Despite the increasing trend over the past few years, in 2012, the reported incidence was only 5.14 per 100,000 in a large US VA cohort (6). However, the cirrhotic ALD population repeatedly shows a much higher annual incidence, ranging from 1.1-2.9\% in multiple cohorts $(7,30,33)$. A 10-year cumulative incidence rate of ALDHCC has been reported at 8.4\% (30) while a 5-year accumulative incidence of cirrhotic ALDHCC was found to be $5.7 \%$ in Brazil (27) and $12.3 \%$ in Japan (26). Older age, male gender, high baseline AFP, high bilirubin, low platelet count, and elevated prothrombin time value were all associated with a higher risk of HCC in alcoholic cirrhosis patients $(7,33)$.

Overall, these results reveal a high annual incidence of $\mathrm{HCC}$ in alcoholic cirrhosis suggesting that HCC screening would be cost-effective, may reduce HCC-related mortality 
Table 2 Prevalence and incidence of ALDHCC

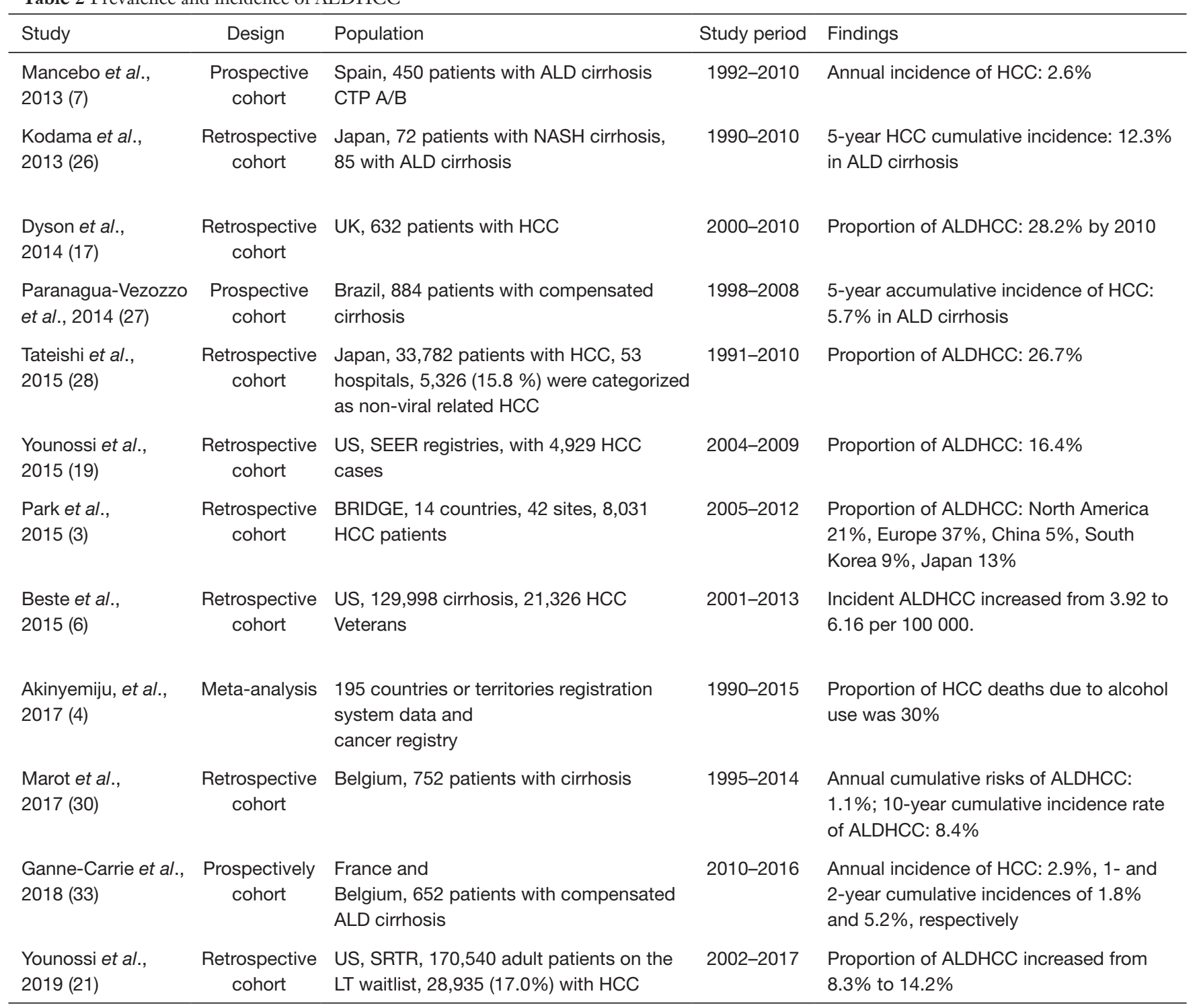

and improve survival.

\section{HCC tumorigenesis}

\section{What drives NAFLDHCC?}

Instead of the well-established two-hit hypothesis, a multi-parallel hit theory seems to better explain NASH development and its progression to HCC. It is thought that NASH and HCC are consequences of numerous in parallel acting conditions including genetic alterations, abnormal lipid metabolism, chronic hyperinsulinemia, altered bile acids, oxidative/endoplasmic reticulum (ER) stress, mitochondrial dysfunction, altered immune system, and dysbiosis in gut microbiota (34). According to this theory, hepatic inflammation is the first cause of fibrosis progression in NASH and HCC development. As in any other chronic liver disease with progression to cirrhosis there is increased cell turnover through mitosis with its potential thread of genetic alterations.

\section{NAFLDHCC and obesity}

Obesity rates have increased dramatically in the US adult population, from $15 \%$ in 1980 to $35 \%$ in 2010 . Adipose 
tissue stimulates release of proinflammatory cytokines with a subsequent chronic low-grade inflammatory state. These cytokines in combination with insulin stimulate pro-oncogenic pathways via JNK, NF-kB, the mammalian target of rapamycin (mTOR), and extracellular signalregulated kinases. Multiple case-control and populationbased studies have shown an association between excess weight and increased risk of HCC. A systematic review of 10 cohort studies with 7 million participants confirmed the positive association between obesity and HCC risk [relative risk (RR):1.4-4.1]. A meta-analysis estimated a summary RR of HCC of 1.17 [95\% confidence interval (CI):1.02-1.34] for overweight persons and 1.89 (95\% CI: 1.51-2.36) for obese individuals compared with normal weight people (35). In a prospective study of 900,000 US adults by Calle et al., a body mass index (BMI) of greater than $35 \mathrm{~kg} / \mathrm{m}^{2}$ was linked to a 4.5 times higher HCC related mortality in men and 1.7 higher risk in women, respectively compared with people with a normal BMI (36). A Danish record linkage study (37) and a metanalysis of European studies (38) showed similar results. Despite strong evidence supporting an association between obesity and HCC comparison of results between different study populations is difficult subsequently impacting their wider generalization. The majority of studies lack adjustments for potential confounders (alcohol, viral hepatitis, other etiologies) or certain categorical variables (gender, age, ethnicity).

Visceral adipose fat deposition often measured by waist to hip ration (WHR) plays a special role in HCC development and outcome. In the EPIC study, the WHR was associated with a 3.5 times higher HCC risk in those with a WHR in the upper tertile (RR: 3.5; $95 \%$ CI: 2.09-5.87; $\mathrm{P}<0.0001$ ) (39). Japanese patients with increased abdominal fat had a two-fold higher HCC recurrence after initial curative radiofrequency ablation (40). A large retrospective cohort study of 1,257 HCC patients confirmed visceral adiposity as an independent predictor of mortality and that body composition rather than BMI determines prognosis in patients with HCC (41).

Obesity increases the HCC risk in patients with cirrhosis from other etiologies than NAFLD; for example in ALD and antecedent steatosis, the risk of HCC was found to be 3.2 times higher than in alcoholic cirrhosis alone (15).

\section{NAFLDHCC and MetS}

MetS is defined by the US National Cholesterol Education Program Adult Treatment Panel III as the presence of at least three of the following conditions: elevated waist circumference/central obesity, dyslipidemia, elevated triglycerides, lowered high-density lipoprotein, hypertension, and impaired fasting glucose. An US study of the SEER-Medicare-linked database showed a twofold increased prevalence of MetS among patients with HCC (37.1 vs. $17.1 \%, \mathrm{P}<0.0001$ ); even after adjusting for other factors a significant association with HCC was found [odds ratio (OR) 2.13; 95\% CI: 1.96-2.31, $\mathrm{P}<0.0001)$ suggesting a primary causative effect (42). Dyson et al. reported that $66 \%$ of patients with HCC had one or more metabolic risk factors (17). IR is a key factor in HCC development and prognosis as evidenced by case series (43) and cohort studies (44-48). Diabetes was an independent risk factor for the development of HCC in 12 cohort studies after adjustment for viral and alcoholic confounders (49). Hyperinsulinemia leads to reduced level of insulin growth factor-binding proteins and subsequent increased levels of bioavailable insulin growth factor 1 (IGF-1) (50) leading to cell proliferation and altered apoptosis. Chun et al. reported that in patients with HCC IGF level was not influenced by cause of liver disease; but increased IGF-1 expression in liver tissue adjacent to HCC was linked to poorer survival after resection (median survival 22 vs. 72 months, $\mathrm{P}<0.006)$ (51). Takuma et al. reported an increased risk for HCC recurrence after curative therapy in patients with diabetes (52). Cohort studies from Greece (46) and Scandinavia $(44,45)$ demonstrated an increased risk of HCC among patients with diabetes. Another large longitudinal US study reported a HCC incidence rate of 2.39 vs. 0.87 per 100,000 persons per year favoring a causal relationship with diabetes preceding HCC development as well as an increasing risk depending on the length of diabetes, yet independent of alcohol use or concomitant viral hepatitis (53). A meta-analysis showed that diabetes was significantly associated with HCC in case control studies (pooled OR $=2.5$; 95\% CI: $1.8-3.5$ ) as well as cohort studies (pooled risk ratio: 2.5 ; $95 \%$ CI: 1.9-3.2) in different populations and different geographic locations (47). Another study of 185 HCC cases and 404 controls documented that diabetes (OR: 4.33; 95\% CI: 1.89-9.86) and obesity (OR:1.97; 95\% CI: 1.03-3.79) increased HCC risk (54). Diabetes also increased HCC risk in person with hepatitis C (RR: 3.52 ; $95 \%$ CI: 1.29-9.24) and hepatitis B infection (RR: 2.27; 95\% CI: 1.10-4.66) (43). As expected, a combination of diabetes and cirrhosis demonstrated the highest risk of HCC (RR: 82.25; 95\% CI: 76.84-94.58) (55). A large population based study 
including 578,700 persons from Norway, Sweden, and Austria showed a RR of HCC of 2.13 (95\% CI: 1.55-2.94) in those with diabetes (56). In another large case-control study using the SEER-Medicare-linked database with adjustments made $\mathrm{HCV}, \mathrm{HBV}$, alcoholic liver disease, and hemochromatosis, diabetes was associated with a threefold higher risk of HCC. Even in patients without other risk factors, the diabetes-adjusted OR remained significant elevated (adjusted OR $=2.87$; 95\% CI: 2.49-3.30) (48). In patients with HCV the cumulative probability of death after 10-year follow-up was higher in patients with diabetes regardless of the presence of HCC although diabetes significantly increased the risk for transition from "startto-HCC" (adjusted hazard ratio aHR $=1.36 ; 95 \%$ CI: 1.16-1.59; $\mathrm{P}<0.001$ ), "start-to-death" ( $\mathrm{aHR}=2.61 ; 95 \% \mathrm{CI}$ : 2.05-3.33; $\mathrm{P}<0.001)$, and "HCC-to-death" $(\mathrm{aHR}=1.36$; 95\% CI: $1.10-1.68 ; \mathrm{P}=0.005)$ (57).

Diabetes seems to increase the risk of HCC by two- to three-fold overall, but especially in the presence of other risk factors. Ethnicity may play a role. African Americans known to have a higher prevalence of obesity and diabetes had a higher risk of HCC compared with persons of European descent; although they had a fourfold lower incidence of NAFLD-related cirrhosis (58). Discrepancies between reported results from available studies may be due to underlying differences in the study design, study populations, sample size, defining diagnoses, course, and treatment of diabetes. A generalized causal link between IR, diabetes, and HCC cannot be established, yet and no data are linking HCC with the degree of IR or lack of diabetes control. It remains uncertain if optimal control of metabolic factors including diabetes reduces HCC risk and if and how diabetes therapy with exogenous insulin impact development and growth of HCC.

\section{NAFLDHCC and its association with IR, ER and oxidative stress}

IR promotes carcinogenesis through ER and oxidative stress. Animal studies have provided solid evidence for the close association between IR, adiponectin, and leptin on a cellular level and shown that liver steatosis, fibrosis and hyperplastic nodules develop in adiponectin knockout mice compared to wild type mice (58). Leptin stimulates neovascularization through VEGF leading to liver fibrosis and HCC in NASH (59). IR inhibits hepatic mitochondrial fatty acid oxidation with subsequent higher level of intracellular fatty acids causing oxidative DNA damage (60) at the $p 53$ gene, a well-known mutational hotspot in HCC (61). Reactive oxygen species (ROS) activate fibrosis. HCC can develop when oxidative injury occurs and oxidative stress inactivates expression of the $\mathrm{Nrf1}$ gene which regulates gene transcription encoding enzymatic antioxidants. Ishii et al. showed that eicosapentaenoic acid (EPA) counteracts steatohepatitis leading to reduced level of serum ROS and inhibited HCC development suggesting that therapy with EPA may reduce the risk of HCC development in patients with NASH (59).

\section{The risk of alcohol and $\mathrm{HCC}$}

Ethanol is classified as a carcinogen and acts synergistically with other risk factors. Intake of more than $50 \mathrm{~g} / \mathrm{day}$ of ethanol exhibited 1.4-fold risk for HCC. ALDHCC develops with advanced liver disease and fibrosis. Animal models have demonstrated that alcoholic steatohepatitis accelerates development of HCC by up-regulating inflammation, cell proliferation, stemness, and miR-122 loss (60). Genetic variations in the alcohol metabolizing enzymes responsible for the amount of the resulting carcinogenic aldehyde are thought as potential inherited markers of HCC. Patients with ALD homozygous for the $A D H 1 C^{*} 1$ allele seems to be more vulnerable to HCC. The weakly active $A L D H 2 * 2$ allele has been associated with HCC in moderate-to-heavy drinkers. Specifically, the $A L D H 2 * 2$ phenotype has a distinct geographical distribution being present in $50 \%$ of the eastern Asian population $(61,62)$.

Oxidative stress due to ROS derived from alcohol metabolism, inflammation and increased iron storage has been identified as an important mechanism in hepatocarcinogenesis. ROS damages cellular macromolecules and forms lipid peroxides promoting HCC. It also stimulates production of cytokines, immune processes and upregulates angiogenesis. Accumulation of ROS affects DNA structurally and functionally with subsequent cell cycle arrest and apoptosis. Genetic alteration such as dimorphism in the $2 G-M P O$ alleles in combination with at least one Ala-SOD2 allele were found to be independent risk factors for HCC (63) and linked to hepatic iron overload which also is associated with an increased risk of HCC along with the usual HFE gene mutations (64).

Alcohol disturbs production of s-adenosyl-L-methionine (SAMe) and maintenance of methylation status which are directly linked to HCC development $(65,66)$ In animal 
models, administration of SAMe showed reduced tumor progression (67) however SAMe did not provide any meaningful benefits for treatment of ALD. Potential therapeutic value in preventing progression of HCC needs to be clarified further (68).

\section{The genetic background and its role in ALD, NAFLD and related $\mathrm{HCC}$}

Genome-wide expression profiling has substantially helped to identify novel diagnostic and prognostic molecular biomarkers. Associations between genetics and HCC in ALD and NAFLD are summarized in Table 3.

Gene regulatory networks facilitate the understanding of the underlying molecular mechanisms of disease progression by defining pathways from upstream regions (UR) to downstream targets from carcinogenesis, angiogenesis, metastasis, and epithelial-mesenchymal transition. These regulatory networks are considerably different between HCC related to different etiologies. In HBC-related HCC, UR showed activated E2F1 which regulates genes involved in cell cycle and DNA replication, while $H N F 4 A$ and $H N F 1 A$ were found as inhibited UR. In HCV-related HCC, interferon- $\gamma$ was activated, while IL1RN, a mitogenactivated protein kinase was inhibited. In ALDHCC, $E R B B 2$ which regulates inflammatory response and cellular movement was activated and both HNF4A and NUPR1 were inhibited. In NAFLDHCC, miR-1249-5p was activated, while NUPR1 involved in cell cycle and apoptosis was inhibited. Determining the potential prognostic value of genes in these regulatory networks seems promising and warrants further investigation.

Single nucleotide polymorphisms (SNPs) in genes encoding for alcohol and lipid metabolism are clearly different in ALD and NAFLD. The rs738409 polymorphism (encoding I148M) in the patatin-like phospholipase 3 (PNPLA3) gene has been identified as an important genetic factor (Table 3). The PNPLA3 $G$ allele was found to be associated with the development and progression of both ALD and NAFLD. A recent study on 318 Japanese patients with cirrhosis and HCC investigating genotype frequencies of 10 SNPs found that the genotype TT of the frequency of the potassium voltage-gated channel subfamily $Q$ member 1 (KCNQ1) was increased significantly in ALD-related cirrhosis but not in non-cirrhotic ALD. PNPLA3 genotype $C C$ was decreased significantly in NAFLD-related cirrhosis. A comparison of patients with and without HCC showed that the KCNQ1 genotype TT was increased significantly in
ALDHCC and NAFLDHCC. Strong associations between the KCN715 genotype GG and ALDHCC and the $G$ allele of PNPLA3 and NAFLDHCC were identified (49).

\section{Gut microbiota an emergent contributor in ALDHCC and NAFLDHCC}

Among the numerous mechanisms associated with the pathophysiology of HCC (Figure 1) the gut microbiome has emerged as an important contributor (34). Obesity, diet, alcohol, and genetics affect the microbiome resulting in intestinal bacterial overgrowth, dysbiosis, impaired intestinal permeability, bacterial translocation and endotoxemia which potentiate hepatic injury including those from NAFLD and ALD (76) and contribute to development of HCC. Dysbiosis boosts the secretion of inflammatory cytokines (TNF- $\alpha$, IL-8, IL1 $\beta$,) by Kupffer cells stimulating lipid accumulation and cell death in hepatocytes, leading to NAFLD, NASH and cirrhosis (77). Dysbiosis promotes the development of NAFLDHCC by altering bile acid metabolism. A change in the composition of the gut microbiota leads to increased deoxycholic acid, which innervates the senescence-associated secretory phenotype of stellate cells resulting in increased secretion of inflammatory and tumor promoting factors stimulating HCC progression (78). In animal models, accumulation of cholesterol and secondary bile acids promoted hepatic inflammation and injury stimulating carcinogenesis (79). Increased level of lipopolysaccharide (LPS) were found to be a mediator of inflammation-associated HCC (80). Dapito et al. reported that TLR-4 (toll-like-receptor) and intestinal microbiota were not required for HCC initiation but for HCC promotion by stimulating proliferation and preventing apoptosis (81). Gut sterilization in advanced liver injury reduced development of HCC, suggesting that intestinal microbiota and TLR-4 represent potential therapeutic targets for HCC prevention in advanced liver disease (81). Probiotic treatment reduced HCC growth and tumor size by decreasing the Th17 cell level and the production of IL-17 in a mouse model of HCC (82).

The gut flora composition is critically involved in the pathogenesis of HCC by creating an anti-inflammatory microenvironment. Certain species (Oscillibacter, Bacteroides, Parabacteroides) stimulate anti-inflammatory IL-10 production (82); others (Alistipes shabii) tends to modulate the gut and reducing tumor growth (82).

Dietary fiber has been linked to icteric HCC in dysbiotic mice while inhibition of gut fermentation and exclusion 
Table 3 Association between genetics, ALDHCC and NAFLDHCC

\begin{tabular}{|c|c|c|c|c|}
\hline Study & Design & Population & Findings & Conclusion \\
\hline $\begin{array}{l}\text { Falleti } \\
\text { et al., } \\
2011(70)\end{array}$ & $\begin{array}{l}\text { Retrospective } \\
\text { cohort; } \\
\text { Genotyped } \\
\text { PNPLA } \\
\text { rs738409 } \\
\text { frequency }\end{array}$ & $\begin{array}{l}\text { Italy, } 483 \text { cirrhotic } \\
\text { patients, } \\
279 \text { underwent LT }\end{array}$ & $\begin{array}{l}\text { Cirrhosis: HCC patients more likely to be } \mathrm{G} / \mathrm{G} \text { homozygotes } \\
\text { (26\%) compared with non-HCC patients }(16 \%, \mathrm{P}<0.02) \\
\text { PNPLA3 rs } 738409 \text { polymorphism was independent predictor of } \\
\text { HCC occurrence (OR: } 1.76, \mathrm{P}<0.05) \text {; Association between the } \\
\text { PNPLA3 rs } 738409 \mathrm{C}>\mathrm{G} \text { polymorphism and HCC was mainly } \\
\text { driven by gender; male with higher HCC risk }(43.1 \%) \text { in } \mathrm{G} / \mathrm{G} \\
\text { homozygous carrier compared with female }(30.4 \%)\end{array}$ & $\begin{array}{l}\text { PNPLA } 3 \text { rs } 738409 ; \\
\text { C > G polymorphism } \\
\text { is associated with } \\
\text { cirrhosis. In synergy } \\
\text { with gender, it is a } \\
\text { strong predictor of HCC } \\
\text { in cirrhosis patients. }\end{array}$ \\
\hline $\begin{array}{l}\text { Singal } \\
\text { et al., } \\
2014(72)\end{array}$ & Metanalysis & $\begin{array}{l}\text { Literature search } \\
\text { for PNPLA3. Total } \\
24 \text { studies, with } \\
9,915 \text { patients } \\
\text { included }\end{array}$ & $\begin{array}{l}\text { PNPLA3 was associated with fibrosis severity. Among nine } \\
\text { studies, with 2,937 patients, PNPLA3 was associated with } \\
\text { increased risk of HCC in cirrhosis patients (OR: } 1.40 ; 95 \% \\
\text { Cl 1.12-1.75). Increased risk of HCC in patients with NASH } \\
\text { or ALD cirrhosis (OR: } 1.67 ; 95 \% \mathrm{Cl}: 1.27-2.21) \text {, not in other } \\
\text { etiologies of cirrhosis (OR 1.33; } 95 \% \mathrm{Cl} \text { : } 0.96-1.82)\end{array}$ & $\begin{array}{l}\text { PNPLA3 is associated } \\
\text { with fibrosis progression } \\
\text { in all etiologies; PNPLA3 } \\
\text { is an independent risk } \\
\text { factor for HCC in NASH } \\
\text { and ALD }\end{array}$ \\
\hline $\begin{array}{l}\text { Guyot } \\
\text { et al., } \\
2013(74)\end{array}$ & $\begin{array}{l}\text { Prospective } \\
\text { study }\end{array}$ & $\begin{array}{l}\text { France, } 279 \text { ALD } \\
\text { cirrhosis and } \\
253 \text { HCV cirrhosis; } \\
\text { Genotyped } \\
\text { PNPLA3 rs } 738409\end{array}$ & $\begin{array}{l}\text { PNPLA3 rs738409 (G/G) was an independent predictor for } \\
\text { HCC in ALD cirrhosis (HR =1.72; 95\% Cl: } 1.21-2.45) \text {, log rank } \\
=0.002) \text { as well as gender, age, high BMI. PNPLA3 rs } 738409 \\
\text { genotypes did not influence the risk of HCC in HCV cirrhosis }\end{array}$ & $\begin{array}{l}\text { PNPLA3 rs } 738409 \\
\text { (G/G) is associated with } \\
\text { greater risk of HCC in } \\
\text { ALD cirrhosis }\end{array}$ \\
\hline $\begin{array}{l}\text { Paradis } \\
\text { et al., } \\
2013(75)\end{array}$ & $\begin{array}{l}\text { Clinical and } \\
\text { basic research }\end{array}$ & $\begin{array}{l}\text { France, } 20 \mathrm{HCC} \\
\text { patients with } \\
\text { MetS vs. } 10 \mathrm{HCC} \\
\text { patients with HCV } \\
\text { cirrhosis }\end{array}$ & $\begin{array}{l}\text { Amplification of chromosome region } 6 p 21.1 .6 p 21.1 \text { most } \\
\text { common overall; more common in MetSHCC (60\%) compared } \\
\text { with HCVHCC }(20 \%, \mathrm{P}<0.01) \text {. Cullin7 (CUL7), at the } 6 p 21.1 \\
\text { locus upregulated in HCC with the } 6 p 21.1 \text { amplicon, in parallel } \\
\text { with a decrease in cyclin D1 expression. Cyclin D1 negative } \\
\text { regulated by CUL7 and function to decrease cell proliferation } \\
\text { and increased apoptosis }\end{array}$ & $\begin{array}{l}\text { CUL7 as a novel gene } \\
\text { potentially involved in } \\
\text { liver carcinogenesis } \\
\text { associated with MetS; } \\
\text { amplification of CUL7 } \\
\text { might promote HCC cell } \\
\text { proliferation }\end{array}$ \\
\hline
\end{tabular}




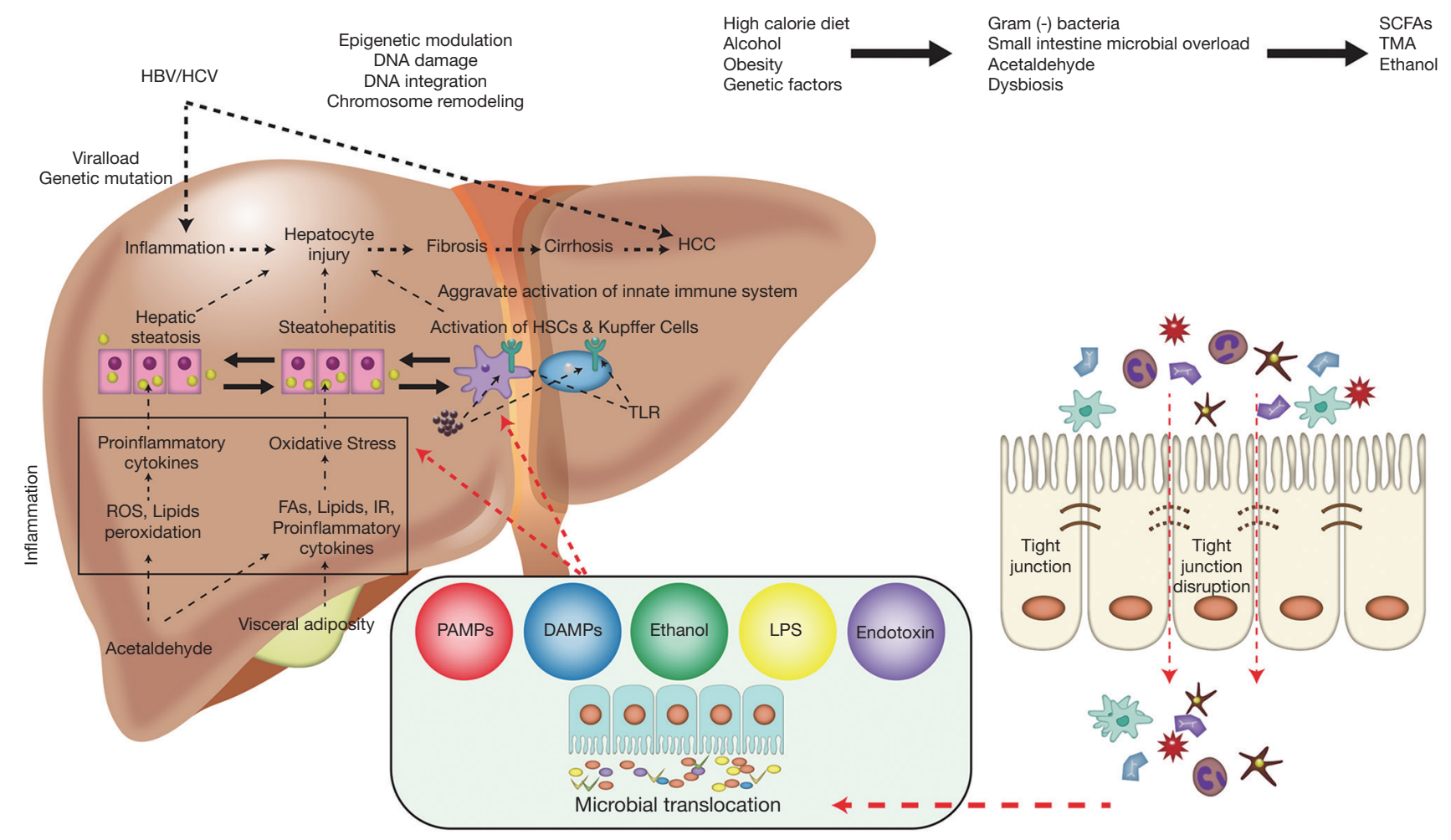

Figure 1 Alcohol, diet, obesity, and genetic factors-all affect gut microbiota leading to dysbiosis with intestinal bacterial overgrowth, increased intestinal permeability with subsequent bacterial translocation and endotoxemia stimulating development of HCC. Figure was created and adapted from Gupta et al. 2019 (34). HCC, hepatocellular carcinoma; HCV, hepatitis C virus; HBV, hepatitis B virus; HSC, hepatic stellate cell; ROS, reactive oxygen species; TLR, toll-like receptor; IR, insulin resistance; LPS, lipopolysaccharide; TNF, tumor necrosis factor; SCFA, short-chain fatty acid; DAMP, damage-associated molecular patterns; PAMPs, pathogen-associated molecular patterns; TMA, trimethylamine.

of dietary soluble fiber prevented HCC. Pharmacologic inhibition of the fermentation or depletion of fermenting bacteria markedly reduced HCC (83).

Chronic alcohol consumption increases intestinal permeability with subsequent high levels of endotoxins and LPS produced by gram-negative bacteria. The mechanisms of alcohol-related liver inflammation and injury have been established, yet the functional processes of the gut microbiota-TLR-4 axis in cirrhosis and HCC, are not well understood, potentially due to obstacles involved in the animal model of ALD.

There is limited information on mechanism of viral hepatitis on altered microbiome mediated HCC although some data suggested that gut microbiota may support virus related inflammation progressing to fibrosis and HCC. Certain Bifidobacterium species were found predominantly in HBV-related cirrhosis. TLR-4 dependent innate immunity influences HBV clearance and TLR-4 induction and activation stipulates carcinogenesis by promoting am additive effect of alcohol and HCV (34).

\section{Excess bepatic iron as risk factor for HCC}

Iron increases oxidative stress, leading to cell toxicity and stimulating pathways involved in fibrogenesis such as lipid peroxidation with production of malondialdehyde, an important activator of hepatic stellate cells and carcinogenesis (84). Excess hepatic iron deposition is caused by increased iron influx due to hepcidin deficiency as seen in hereditary hemochromatosis (C282YHFE mutation). Lauret et al. (85) showed that HCC patients with alcoholinduced cirrhosis had a greater frequency $(20.9 \%)$ of C282Y heterozygosity than patients with alcohol-induced cirrhosis without HCC (4.4\%). Overall, C282Y heterozygosity leads to minor increased iron levels, which however may be important during heavy alcohol consumption as chronic 
alcohol abuse increases intestinal iron absorption. ROS from free iron, DNA strand breaks, p5 3 mutation, and DNA adducts, are all factors that promote HCC related to iron overload (86).

Hepatic iron deposit is also thought a risk factor for HCC in NASH cirrhosis. In a retrospective study of liver biopsies of 153 patients (51 with HCC) matched for age, sex, stage of liver disease) iron deposits were low with corrected total iron score (Deugnier score) of equal or lower than 33 (range: 0-60). The iron score was significantly higher in NASHHCC compared with patients without HCC (87). Phlebotomy to reduce excess iron storage can been done; some date suggesting it may reduce risk of HCC. Nirei et al. (88) reported a significantly lower HCC incidence in HCV patients receiving phlebotomy (10.3\%) compared with those without phlebotomy (43.7\%) during an 8-year follow-up period; even in patients with a normal baseline ferritin level $(0.0 \%$ vs. $36.0 \%)$. The investigators concluded that phlebotomy may be protective against HCC development in these patients by a risk ratio of 0.13 .

An association between iron storage and NAFLD has been evidenced on a molecular level. Iron-induced oxidative DNA damage (hepatic 8-oxodG) was associated with abnormal glucose and insulin level in more severe hepatic steatosis in NASH patients compared with simple steatosis (89). Increased expression of transferrin receptors in surgical HCC samples with higher level of $\alpha$-fetoprotein and gamma carboxyprothrombin $(\mathrm{P}<0.05)(90)$ were reported by Sakuri et al. Controversially, Younossi et al. (19) and Angulo et al. (91) did not find an association between hepatic iron level and fibrosis or significant iron accumulation in NASH patients. Which role hepatic iron in the sequence of progression from NAFLD to NASH to HCC plays remains uncertain; yet, may be important in some patients. Contributing factors including genetics, dysregulation of iron-regulatory pathways, and phagocytosis by Kupffer cells may be responsible for hepatic iron storage in NASH stipulating further studies to clarify the role of excess hepatic iron and whether iron depletion may influence long-term outcome in NAFLD- and NASH-associated HCC.

\section{The synergistic effect of carcinogenesis of ALD and NAFLD on chronic viral hepatitis}

Alcohol can affect HCC progression by acting synergistically at multiple levels (92). There is strong evidence that alcohol intake increases the risk of HCC in $\mathrm{HCV}$ infected persons. In a multivariate analysis lack of virus eradication and alcohol consumption were associated with a 3 -fold increased risk of HCC ( $\mathrm{HR}=3.43 ; 95 \%$ CI: $1.49-7.92, \mathrm{P}=0.004$ ) (93). In diabetic patients, heavy alcohol of greater than $80 \mathrm{~g} /$ day the risk of HCC rose from 2.4 to 9.9 (94). Obesity also has a synergistically effect (60).

Conversely, data suggesting that alcohol cessation reduces HCC risk; however a "washout" period of more than 20 years is needed to achieve the same incidence of HCC seen in abstinent patients (95).

\section{The clinical perspective of NAFLD and ALD related HCC}

\section{Prevention of HCC: what can we do?}

Preventing or reversing obesity, MetS, and diabetes on a population-based level would be a cost-effective way to reduce HCC risk, but remains challenging (1). Lifestyle modifications are recommended to reverse metabolicrelated morbidities. A prospective cohort study of 428,584 persons and 1,668 HCC cases showed a clear risk reduction related to physical activity after 8.5 years of follow-up, and the protective effect correlated with the intensity of physical activity (96). Another large-scale prospective cohort study on a population of 507,897 with a 10 -year follow-up reported similar results (97). Animal studies have established that exercise activates the phosphorylation of AMPK resulting in a down-regulation of mTOR kinase activity (98).

Alcohol is an independent risk factor of HCC and stimulates HCC development in the context of NAFLD. According to Kimura et al. even mild alcohol consumption led to the development of HCC compared with the nonalcohol users (6.5\% vs. 1.4\%) (32). A meta-analysis indicated that HCC risk is reduced by $6-7 \%$ annually after alcohol cessation (95). Therefore, alcohol cessation is a crucial recommendation to both NAFLD and ALD patients. Diet modification may provide additional protection against HCC. Various studies from Asia and Europe showed that a diet rich in green vegetables correlates with a reduced HCC risk speculating that the effect is linked to antioxidants like vitamin C, vitamin E, and selenium (99-101).

More recently, data suggest that in the context of NAFLD, commonly used medications may prevent HCC. Multiple studies have consistently demonstrated that metformin significantly reduces the risk of HCC. Metformin was associated with an estimated $62 \%$ risk reduction of HCC among 105,495 patients with type 
2 diabetes in one study (102); another study showed an estimated $76 \%$ HCC-risk reduction among diabetes patients (103). Sulfonylurea and insulin have been associated with increasing HCC risk in diabetic patients $(103,104)$. Metformin affects incidence of HCC via activation of AMPK phosphorylate with subsequent inhibition of the mTOR pathway and regulating IGFs or other downstream target effectors, a similar process which occurs during physical exercise $(98,105)$. Statins have also shown to reduces HCC risk. A meta-analysis including 10 studies on 4,298 cases of HCC among 1,459,417 patients, concluded that statins are associated with a reduced risk of HCC (OR: 0.63; 95\% CI: 0.52-0.76) in Western and Asian populations (106). As the benefits of metformin and statins seem to extend from metabolic and cardiovascular improvement to perhaps HCC prevention their clinical utility in patients for sole purpose of treating NAFLD needs to be determined.

\section{Screening for HCC in NAFLD/NASH and ALD: is cirrbosis the watershed?}

Since, in the context of NAFLD, HCC can occur before the development of cirrhosis, how to balance the pros of early HCC diagnosis and the cons of unnecessary imaging or potential invasive procedures remains challenging. The American Association for the Study of Liver Diseases recommends a $1.5 \%$ annual incidence cutoff for surveillance of HCC to be efficient. The benefit of surveillance in NAFLD patients is uncertain due to the low incidence of HCC (107). The large-scale, multicenter cohort study conducted by Kawamura et al. reported an annual incidence of NAFLD-related HCC of only $0.043 \%$ (24), and a meta-analysis published by Younossi et al. concluded that the annual incidence of NAFLDHCC was $0.044 \%$ (29). Therefore, conducting HCC surveillance is unlikely to be cost-effective or provide significant clinical benefit in terms of reducing mortality in NAFLD patients without significant fibrosis (107). However, once NAFLD has advanced to cirrhosis, the incidence of HCC increases significantly. Ascha et al. reported an annual cumulative incidence of HCC in a prospective study with 195 cases of NASH cirrhosis of 2.6\% (14); Yatsuji et al. indicated a 5 -year cumulative incidence of HCC in cirrhotic NASH patients of $11.3 \%$ (23). Thus, HCC surveillance benefits the cirrhotic NASH patient (107). Whether to conduct HCC surveillance in a patient with NASH with advanced fibrosis remains controversial. Hashimoto et al. (108) reported a 5 -year cumulative incidence of HCC of $7.6 \%$ in a prospective cohort of NASH patients with advanced fibrosis making it difficult to yield a definitive conclusion based on current guideline recommendations and evidence. More high-quality studies are needed to reach consensus.

ALDHCC incidence rate is also low with $0.039 \%$ to $0.062 \%$ (6). Therefore surveillance is not recommended for patients with ALD without cirrhosis. However, multiple cohort studies have indicated that cirrhotic ALD has an annual HCC incidence rate between $1.1 \%$ and $2.9 \%$ $(7,30,33)$, which is significant enough to initiate HCC screening.

To date, it is recommended that all adult patients with cirrhosis, regardless of etiology, should undergo HCC surveillance (107).

\section{Management and outcome of NAFLD/NASH- and ALD- associated HCC: similar or different?}

Both the American Association for the Study of Liver Diseases and European Association for Study of the Liver recommend the same therapeutic strategy for HCC regardless of etiology. These strategies can be categorized into (I) curative therapy that includes surgical resection, orthotopic LT, and thermal/radiofrequency ablation and (II) noncurative therapies with transarterial chemoembolization, transarterial radioembolization, stereotactic body radiation therapy, and systemic chemotherapy $(107,109)$.

As NAFLD and ALD patients often have poor HCC surveillance tumors are found at a later stage challenging potential curative treatment. Patients with NAFLDHCC have co-existing metabolic and cardiovascular comorbidities and are often elderly. Tumors are often larger with advanced TNM stage compared with HCC arising from other chronic liver diseases $(17,19,110)$. Younossi et al. reported a shorter survival time (NAFLD 14.17; HCV 17.85; HBV 21.45 months) and a higher 1-year mortality rate (NAFLD 61.2\%; HCV 43.7\%; HBV 51.3\%) in NAFLDHCC compared with viral hepatitis related HCC (19). However, most studies showed a similar survival despite patients having an older age at presentation $(17,28,111)$ and after matching patients with each tumor stage, a similar prognosis to other HCC etiologies. An Italian multicenter prospective survey reported that NAFLDHCC had reduced survival compared with HCVHCC (25.5 vs. 33.7 months) however after strictly patient matching with each tumor stage to eliminate possible confounders, results showed no significant differences between the two groups (112). Multiple studies did not demonstrate an inferior prognosis 
of NAFLDHCC after surgical resection. Piscaglia et al. reported no significant difference in survival duration between NAFLDHCC and HCVHCC after curative treatments (112). Reddy et al. conducted a retrospective cohort study, enrolling 303 patients who underwent curative HCC treatment between 2000 and 2010 and determined that NASH has a recurrence-free survival rate similar to that of $\mathrm{HCV}$ and ALD. Overall survival of NASHHCC patients after curative treatment was superior compared to HCV and ALDHCC patients; most likely secondary to less severe liver dysfunction at HCC diagnosis (113). Similar findings were reported in a multiple-center matching analysis that enrolled more than 1,500 cases of surgical HCC resection. Morbidity and liver failure rates were similar between HCC and NAFLD groups, and steatohepatitis was not a major predictor of severe morbidity and liver failure. NAFLDHCC had a slightly better 5 -year overall survival rate $(65.6 \%$ vs. $61.4 \%)$ and recurrence-free survival rate $(37.0 \%$ vs. $27.5 \%)$ after resection compared with HCVHCC (114).

Some studies reported a poor prognosis for ALDHCC. In the SEER database, compared with $\mathrm{HCV}, \mathrm{HBV}$, and NAFLD, ALDHCC had the shortest survival time and highest 1-year mortality rate (19). Two recent large-scale European studies utilizing the Barcelona Clinic Liver Cancer (BCLC) staging system and comparing ALDHCC with HCVHCC revealed different results. Using the Italian Liver Cancer (ITA.LI.CA) database and including 1,642 HCV and 573 ALDHCC patients diagnosed between 2000 and 2012 patients with ALDHCC had a significantly shorter median overall survival compared with patients with HCVHCC (27.4 vs. 33.6 months). However, the influence of etiology disappeared when survival was assessed in each BCLC stage; Cox regression multivariate models indicated that ALDHCC did not have worse treatment outcome compared with its HCV counterpart. A French prospective study on 894 patients with HCC diagnosed between 2008-2009, and 5-year follow-up reported similar results. ALDHCC had a significantly shorter survival duration compared with non-ALD-related HCC (5.7 vs. 9.7 months). However, the prognostic difference disappeared when survival was assessed at each BCLC stage (115).

Based on current evidence, it appears that poor surveillance of patients with ALD results in a delay in cancer diagnosis and is associated with more advanced HCC stage as well as worse liver function at presentation. These factors, rather than cancer aggressiveness, adversely affect the prognosis and clinical outcome compared with other
HCC etiologies, which all have similar survival durations within each tumor stage.

Potential biomarker to identify patients with ALD and NASH at risk for progression to cirrhosis and HCC would be beneficial, yet multifactorial nature of these entities and limited number of sufficiently powered studies are among the current limitations for validated biomarkers of clinical utility (116).

\section{Conclusions}

HCCs in alcoholic and non-alcoholic liver disease share similar genetic and epigenetic hallmarks; yet also have distinct features. Underlying culprits act synergistically potentiating liver injury and HCC risk. Patients with ALD and NAFLD related cirrhosis should be included in HCC surveillance programs. Genetic variants associated with a higher risk of HCC may potentially offer the unique opportunity of individualized therapy. To date, large prospective cohort studies of patients with ALD and NAFLD including the use of biobanking is an unmet need. We need to better stratify patients into different HCC risk classes and facilitate early detection of tumors amenable to potential curative treatment. Conclusively, we need to better understand how different genetic markers, epigenetic alterations, dynamic changes of potential biomarkers in combination with clinical data may affect the management and outcome of these patients.

\section{Acknowledgments}

None.

\section{Footnote}

Conflicts of Interest: The authors have no conflicts of interest to declare.

Ethical Statement: The authors are accountable for all aspects of the work in ensuring that questions related to the accuracy or integrity of any part of the work are appropriately investigated and resolved.

\section{References}

1. Bray F, Ferlay J, Soerjomataram I, et al. Global cancer statistics 2018: GLOBOCAN estimates of incidence and mortality worldwide for 36 cancers in 185 countries. CA Cancer J Clin 2018;68:394-424. 
2. Altekruse SF, McGlynn KA, Reichman ME. Hepatocellular carcinoma incidence, mortality, and survival trends in the United States from 1975 to 2005 . J Clin Oncol 2009;27:1485-91.

3. Park JW, Chen M, Colombo M, et al. Global patterns of hepatocellular carcinoma management from diagnosis to death: the BRIDGE Study. Liver Int 2015;35:2155-66.

4. Global Burden of Disease Liver Cancer C, Akinyemiju T, Abera S, et al. The Burden of Primary Liver Cancer and Underlying Etiologies From 1990 to 2015 at the Global, Regional, and National Level: Results From the Global Burden of Disease Study 2015. JAMA Oncol 2017;3:1683-91.

5. Farrell GC, Wong VW, Chitturi S. NAFLD in Asia-as common and important as in the West. Nat Rev Gastroenterol Hepatol 2013;10:307-18.

6. Beste LA, Leipertz SL, Green PK, et al. Trends in burden of cirrhosis and hepatocellular carcinoma by underlying liver disease in US veterans, 2001-2013. Gastroenterology 2015;149:1471-82 e5; quiz e17-8.

7. Mancebo A, Gonzalez-Dieguez ML, Cadahia V, et al. Annual incidence of hepatocellular carcinoma among patients with alcoholic cirrhosis and identification of risk groups. Clin Gastroenterol Hepatol 2013;11:95-101.

8. Naveau S, Giraud V, Borotto E, et al. Excess weight risk factor for alcoholic liver disease. Hepatology 1997;25:108-11.

9. Adams LA, Lymp JF, St Sauver J, et al. The natural history of nonalcoholic fatty liver disease: a population-based cohort study. Gastroenterology 2005;129:113-21.

10. Pimpin L, Cortez-Pinto H, Negro F, et al. Burden of liver disease in Europe: Epidemiology and analysis of risk factors to identify prevention policies. J Hepatol 2018;69:718-35.

11. Singal AG, El-Serag HB. Hepatocellular Carcinoma From Epidemiology to Prevention: Translating Knowledge into Practice. Clin Gastroenterol Hepatol 2015;13:2140-51.

12. Brar G, Tsukamoto H. Alcoholic and non-alcoholic steatohepatitis: global perspective and emerging science. J Gastroenterol 2019;54:218-25.

13. Morgan TR, Mandayam S, Jamal MM. Alcohol and hepatocellular carcinoma. Gastroenterology 2004;127:S87-96.

14. Ascha MS, Hanouneh IA, Lopez R, et al. The incidence and risk factors of hepatocellular carcinoma in patients with nonalcoholic steatohepatitis. Hepatology 2010;51:1972-8.

15. Nair S, Mason A, Eason J, et al. Is obesity an independent risk factor for hepatocellular carcinoma in cirrhosis? Hepatology 2002;36:150-5.

16. Cho EJ, Kwack MS, Jang ES, et al. Relative etiological role of prior hepatitis $B$ virus infection and nonalcoholic fatty liver disease in the development of non-B non-C hepatocellular carcinoma in a hepatitis B-endemic area. Digestion 2011;84 Suppl 1:17-22.

17. Dyson J, Jaques B, Chattopadyhay D, et al. Hepatocellular cancer: the impact of obesity, type 2 diabetes and a multidisciplinary team. J Hepatol 2014;60:110-7.

18. Wong RJ, Cheung R, Ahmed A. Nonalcoholic steatohepatitis is the most rapidly growing indication for liver transplantation in patients with hepatocellular carcinoma in the U.S. Hepatology 2014;59:2188-95.

19. Younossi ZM, Otgonsuren M, Henry L, et al. Association of nonalcoholic fatty liver disease (NAFLD) with hepatocellular carcinoma (HCC) in the United States from 2004 to 2009. Hepatology 2015;62:1723-30.

20. Sadler EM, Mehta N, Bhat M, et al. Liver Transplantation for NASH-Related Hepatocellular Carcinoma Versus Non-NASH Etiologies of Hepatocellular Carcinoma. Transplantation 2018;102:640-7.

21. Younossi Z, Stepanova M, Ong JP, et al. Nonalcoholic Steatohepatitis Is the Fastest Growing Cause of Hepatocellular Carcinoma in Liver Transplant Candidates. Clin Gastroenterol Hepatol 2019;17:748-55.e3.

22. Hashimoto E, Yatsuji S, Tobari M, et al. Hepatocellular carcinoma in patients with nonalcoholic steatohepatitis. J Gastroenterol 2009;44 Suppl 19:89-95.

23. Yatsuji S, Hashimoto E, Tobari M, et al. Clinical features and outcomes of cirrhosis due to non-alcoholic steatohepatitis compared with cirrhosis caused by chronic hepatitis C. J Gastroenterol Hepatol 2009;24:248-54.

24. Kawamura Y, Arase Y, Ikeda K, et al. Large-scale longterm follow-up study of Japanese patients with nonalcoholic Fatty liver disease for the onset of hepatocellular carcinoma. Am J Gastroenterol 2012;107:253-61.

25. Amarapurkar DN, Dharod M, Gautam S, et al. Risk of development of hepatocellular carcinoma in patients with NASH-related cirrhosis. Trop Gastroenterol 2013;34:159-63.

26. Kodama K, Tokushige K, Hashimoto E, et al. Hepatic and extrahepatic malignancies in cirrhosis caused by nonalcoholic steatohepatitis and alcoholic liver disease. Alcohol Clin Exp Res 2013;37 Suppl 1:E247-52.

27. Paranagua-Vezozzo DC, Ono SK, Alvarado-Mora MV, et al. Epidemiology of HCC in Brazil: incidence and risk factors in a ten-year cohort. Ann Hepatol 2014;13:386-93. 
28. Tateishi R, Okanoue T, Fujiwara N, et al. Clinical characteristics, treatment, and prognosis of non-B, non-C hepatocellular carcinoma: a large retrospective multicenter cohort study. J Gastroenterol 2015;50:350-60.

29. Younossi ZM, Koenig AB, Abdelatif D, et al. Global epidemiology of nonalcoholic fatty liver disease-Metaanalytic assessment of prevalence, incidence, and outcomes. Hepatology 2016;64:73-84.

30. Marot A, Henrion J, Knebel JF, et al. Alcoholic liver disease confers a worse prognosis than $\mathrm{HCV}$ infection and non-alcoholic fatty liver disease among patients with cirrhosis: An observational study. PLoS One 2017;12:e0186715.

31. Vilar-Gomez E, Calzadilla-Bertot L, Wai-Sun Wong V, et al. Fibrosis Severity as a Determinant of Cause-Specific Mortality in Patients With Advanced Nonalcoholic Fatty Liver Disease: A Multi-National Cohort Study. Gastroenterology 2018;155:443-57.e17.

32. Kimura T, Tanaka N, Fujimori N, et al. Mild drinking habit is a risk factor for hepatocarcinogenesis in nonalcoholic fatty liver disease with advanced fibrosis. World J Gastroenterol 2018;24:1440-50.

33. Ganne-Carrie N, Chaffaut C, Bourcier V, et al. Estimate of hepatocellular carcinoma incidence in patients with alcoholic cirrhosis. J Hepatol 2018;69:1274-83.

34. Gupta H, Youn GS, Shin MJ, et al. Role of Gut Microbiota in Hepatocarcinogenesis. Microorganisms 2019. doi: 10.3390/microorganisms7050121.

35. Larsson SC, Wolk A. Overweight, obesity and risk of liver cancer: a meta-analysis of cohort studies. Br J Cancer 2007;97:1005-8.

36. Calle EE, Rodriguez C, Walker-Thurmond K, et al. Overweight, obesity, and mortality from cancer in a prospectively studied cohort of U.S. adults. N Engl J Med 2003;348:1625-38.

37. Moller H, Mellemgaard A, Lindvig K, et al. Obesity and cancer risk: a Danish record-linkage study. Eur J Cancer 1994;30a:344-50.

38. Renehan AG, Tyson M, Egger M, et al. Body-mass index and incidence of cancer: a systematic review and metaanalysis of prospective observational studies. Lancet 2008;371:569-78.

39. Schlesinger S, Aleksandrova K, Pischon T, et al. Abdominal obesity, weight gain during adulthood and risk of liver and biliary tract cancer in a European cohort. Int J Cancer 2013;132:645-57.

40. Ohki T, Tateishi R, Shiina S, et al. Visceral fat accumulation is an independent risk factor for hepatocellular carcinoma recurrence after curative treatment in patients with suspected NASH. Gut 2009;58:839-44.

41. Fujiwara N, Nakagawa H, Kudo Y, et al. Sarcopenia, Intramuscular Fat Deposition, and Visceral Adiposity Independently Predict the Outcomes of Hepatocellular Carcinoma. J Hepatol 2015;63:131-40.

42. Welzel TM, Graubard BI, Zeuzem S, et al. Metabolic syndrome increases the risk of primary liver cancer in the United States: a study in the SEER-Medicare database. Hepatology 2011;54:463-71.

43. Chen CL, Yang HI, Yang WS, et al. Metabolic factors and risk of hepatocellular carcinoma by chronic hepatitis $\mathrm{B} / \mathrm{C}$ infection: a follow-up study in Taiwan. Gastroenterology 2008;135:111-21.

44. Wideroff L, Gridley G, Mellemkjaer L, et al. Cancer incidence in a population-based cohort of patients hospitalized with diabetes mellitus in Denmark. J Natl Cancer Inst 1997;89:1360-5.

45. Adami HO, Chow WH, Nyren O, et al. Excess risk of primary liver cancer in patients with diabetes mellitus. J Natl Cancer Inst 1996;88:1472-7.

46. Lagiou P, Kuper H, Stuver SO, et al. Role of diabetes mellitus in the etiology of hepatocellular carcinoma. J Natl Cancer Inst 2000;92:1096-9.

47. El-Serag HB, Hampel H, Javadi F. The association between diabetes and hepatocellular carcinoma: a systematic review of epidemiologic evidence. Clin Gastroenterol Hepatol 2006;4:369-80.

48. Davila JA, Morgan RO, Shaib Y, et al. Diabetes increases the risk of hepatocellular carcinoma in the United States: a population based case control study. Gut 2005;54:533-9.

49. Rosmorduc O, Fartoux L. HCC and NASH: how strong is the clinical demonstration? Clin Res Hepatol Gastroenterol 2012;36:202-8.

50. Bugianesi E. Non-alcoholic steatohepatitis and cancer. Clin Liver Dis 2007;11:191-207, x-xi.

51. Chun YS, Huang M, Rink L, et al. Expression levels of insulin-like growth factors and receptors in hepatocellular carcinoma: a retrospective study. World J Surg Oncol 2014;12:231.

52. Takuma Y, Nouso K. Nonalcoholic steatohepatitisassociated hepatocellular carcinoma: our case series and literature review. World J Gastroenterol 2010;16:1436-41.

53. El-Serag HB, Tran T, Everhart JE. Diabetes increases the risk of chronic liver disease and hepatocellular carcinoma. Gastroenterology 2004;126:460-8.

54. Turati F, Talamini R, Pelucchi C, et al. Metabolic 
syndrome and hepatocellular carcinoma risk. Br J Cancer 2013;108:222-8.

55. Chen HF, Chen P, Li CY. Risk of malignant neoplasms of liver and biliary tract in diabetic patients with different age and sex stratifications. Hepatology 2010;52:155-63.

56. Borena W, Strohmaier S, Lukanova A, et al. Metabolic risk factors and primary liver cancer in a prospective study of 578,700 adults. Int J Cancer 2012;131:193-200.

57. Huang TS, Lin CL, Lu MJ, et al. Diabetes, hepatocellular carcinoma, and mortality in hepatitis $\mathrm{C}$-infected patients: A population-based cohort study. J Gastroenterol Hepatol 2017;32:1355-62.

58. Browning JD, Kumar KS, Saboorian MH, et al. Ethnic differences in the prevalence of cryptogenic cirrhosis. Am J Gastroenterol 2004;99:292-8.

59. Ishii H, Horie $\mathrm{Y}$, Ohshima S, et al. Eicosapentaenoic acid ameliorates steatohepatitis and hepatocellular carcinoma in hepatocyte-specific Pten-deficient mice. J Hepatol 2009;50:562-71.

60. Grewal P, Viswanathen VA. Liver cancer and alcohol. Clin Liver Dis 2012;16:839-50.

61. Munaka M, Kohshi K, Kawamoto T, et al. Genetic polymorphisms of tobacco- and alcohol-related metabolizing enzymes and the risk of hepatocellular carcinoma. J Cancer Res Clin Oncol 2003;129:355-60.

62. Sakamoto T, Hara M, Higaki Y, et al. Influence of alcohol consumption and gene polymorphisms of ADH2 and ALDH2 on hepatocellular carcinoma in a Japanese population. Int J Cancer 2006;118:1501-7.

63. Nahon P, Sutton A, Rufat P, et al. Myeloperoxidase and superoxide dismutase 2 polymorphisms comodulate the risk of hepatocellular carcinoma and death in alcoholic cirrhosis. Hepatology 2009;50:1484-93.

64. Jin F, Qu LS, Shen XZ. Association between C282Y and H63D mutations of the HFE gene with hepatocellular carcinoma in European populations: a meta-analysis. J Exp Clin Cancer Res 2010;29:18.

65. Villanueva A, Portela A, Sayols S, et al. DNA methylationbased prognosis and epidrivers in hepatocellular carcinoma. Hepatology 2015;61:1945-56.

66. Calvisi DF, Ladu S, Gorden A, et al. Mechanistic and prognostic significance of aberrant methylation in the molecular pathogenesis of human hepatocellular carcinoma. J Clin Invest 2007;117:2713-22.

67. Pascale RM, Simile MM, Satta G, et al. Comparative effects of L-methionine, S-adenosyl-L-methionine and 5 '-methylthioadenosine on the growth of preneoplastic lesions and DNA methylation in rat liver during the early stages of hepatocarcinogenesis. Anticancer Res 1991;11:1617-24.

68. Rambaldi A, Gluud C. S-adenosyl-L-methionine for alcoholic liver diseases. Cochrane Database Syst Rev 2006;(11):Cd002235.

69. Zain SM, Mohamed R, Cooper DN, et al. Genome-wide analysis of copy number variation identifies candidate gene loci associated with the progression of non-alcoholic fatty liver disease. PLoS One 2014;9:e95604.

70. Falleti E, Fabris C, Cmet S, et al. PNPLA3 rs738409C/G polymorphism in cirrhosis: relationship with the aetiology of liver disease and hepatocellular carcinoma occurrence. Liver Int 2011;31:1137-43.

71. Valenti L, Motta BM, Soardo G, et al. PNPLA3 I148M polymorphism, clinical presentation, and survival in patients with hepatocellular carcinoma. PLoS One 2013;8:e75982.

72. Singal AG, Manjunath H, Yopp AC, et al. The effect of PNPLA3 on fibrosis progression and development of hepatocellular carcinoma: a meta-analysis. Am J Gastroenterol 2014;109:325-34.

73. Liu YL, Patman GL, Leathart JB, et al. Carriage of the PNPLA3 rs738409 $\mathrm{C}>\mathrm{G}$ polymorphism confers an increased risk of non-alcoholic fatty liver disease associated hepatocellular carcinoma. J Hepatol 2014;61:75-81.

74. Guyot E, Sutton A, Rufat P, et al. PNPLA3 rs738409, hepatocellular carcinoma occurrence and risk model prediction in patients with cirrhosis. J Hepatol 2013;58:312-8.

75. Paradis V, Albuquerque M, Mebarki M, et al. Cullin7: a new gene involved in liver carcinogenesis related to metabolic syndrome. Gut 2013;62:911-9.

76. Bajaj JS. The role of microbiota in hepatic encephalopathy. Gut Microbes 2014;5:397-403.

77. Miura K, Kodama Y, Inokuchi S, et al. Toll-like receptor 9 promotes steatohepatitis by induction of interleukin-1beta in mice. Gastroenterology 2010;139:323-34.e7.

78. Yoshimoto S, Loo TM, Atarashi K, et al. Obesity-induced gut microbial metabolite promotes liver cancer through senescence secretome. Nature 2013;499:97-101.

79. Yamada S, Takashina Y, Watanabe M, et al. Bile acid metabolism regulated by the gut microbiota promotes non-alcoholic steatohepatitis-associated hepatocellular carcinoma in mice. Oncotarget 2018;9:9925-39.

80. Henao-Mejia J, Elinav E, Jin C, et al. Inflammasomemediated dysbiosis regulates progression of NAFLD and obesity. Nature 2012;482:179-85.

81. Dapito DH, Mencin A, Gwak GY, et al. Promotion of 
hepatocellular carcinoma by the intestinal microbiota and TLR4. Cancer Cell 2012;21:504-16.

82. Li J, Sung CY, Lee N, et al. Probiotics modulated gut microbiota suppresses hepatocellular carcinoma growth in mice. Proc Natl Acad Sci U S A 2016;113:E1306-15.

83. Singh V, Yeoh BS, Chassaing B, et al. Dysregulated Microbial Fermentation of Soluble Fiber Induces Cholestatic Liver Cancer. Cell 2018;175:679-94.e22.

84. George DK, Goldwurm S, MacDonald GA, et al. Increased hepatic iron concentration in nonalcoholic steatohepatitis is associated with increased fibrosis. Gastroenterology 1998;114:311-8.

85. Lauret E, Rodriguez M, Gonzalez S, et al. HFE gene mutations in alcoholic and virus-related cirrhotic patients with hepatocellular carcinoma. Am J Gastroenterol 2002;97:1016-21.

86. Marrogi AJ, Khan MA, van Gijssel HE, et al. Oxidative stress and p53 mutations in the carcinogenesis of iron overload-associated hepatocellular carcinoma. J Natl Cancer Inst 2001;93:1652-5.

87. Sorrentino P, D'Angelo S, Ferbo U, et al. Liver iron excess in patients with hepatocellular carcinoma developed on non-alcoholic steato-hepatitis. J Hepatol 2009;50:351-7.

88. Nirei K, Matsuoka S, Nakamura H, et al. Incidence of hepatocellular carcinoma reduced by phlebotomy treatment in patients with chronic hepatitis C. Intern Med 2015;54:107-17.

89. Fujita $\mathrm{N}$, Miyachi $\mathrm{H}$, Tanaka $H$, et al. Iron overload is associated with hepatic oxidative damage to DNA in nonalcoholic steatohepatitis. Cancer Epidemiol Biomarkers Prev 2009;18:424-32.

90. Sakurai K, Sohda T, Ueda S, et al. Immunohistochemical demonstration of transferrin receptor 1 and 2 in human hepatocellular carcinoma tissue. Hepatogastroenterology 2014;61:426-30.

91. Angulo P, Keach JC, Batts KP, et al. Independent predictors of liver fibrosis in patients with nonalcoholic steatohepatitis. Hepatology 1999;30:1356-62.

92. Kim KR, Moon HE, Kim KW. Hypoxia-induced angiogenesis in human hepatocellular carcinoma. J Mol Med (Berl) 2002;80:703-14.

93. Vandenbulcke H, Moreno C, Colle I, et al. Alcohol intake increases the risk of $\mathrm{HCC}$ in hepatitis $\mathrm{C}$ virus-related compensated cirrhosis: A prospective study. J Hepatol 2016;65:543-51.

94. Hassan MM, Hwang LY, Hatten CJ, et al. Risk factors for hepatocellular carcinoma: synergism of alcohol with viral hepatitis and diabetes mellitus. Hepatology
2002;36:1206-13.

95. Heckley GA, Jarl J, Asamoah BO, et al. How the risk of liver cancer changes after alcohol cessation: a review and meta-analysis of the current literature. BMC Cancer 2011;11:446.

96. Wen CP, Lin J, Yang YC, et al. Hepatocellular carcinoma risk prediction model for the general population: the predictive power of transaminases. J Natl Cancer Inst 2012;104:1599-611.

97. Behrens G, Matthews CE, Moore SC, et al. The association between frequency of vigorous physical activity and hepatobiliary cancers in the NIH-AARP Diet and Health Study. Eur J Epidemiol 2013;28:55-66.

98. Piguet AC, Saran U, Simillion C, et al. Regular exercise decreases liver tumors development in hepatocytespecific PTEN-deficient mice independently of steatosis. J Hepatol 2015;62:1296-303.

99. Montella M, Crispo A, Giudice A. HCC, diet and metabolic factors: Diet and HCC. Hepat Mon 2011;11:159-62.

100. Sauvaget C, Nagano J, Hayashi M, et al. Vegetables and fruit intake and cancer mortality in the Hiroshima/ Nagasaki Life Span Study. Br J Cancer 2003;88:689-94.

101. Yu MW, Hsieh HH, Pan WH, et al. Vegetable consumption, serum retinol level, and risk of hepatocellular carcinoma. Cancer Res 1995;55:1301-5.

102.Zhang ZJ, Zheng ZJ, Shi R, et al. Metformin for liver cancer prevention in patients with type 2 diabetes: a systematic review and meta-analysis. J Clin Endocrinol Metab 2012;97:2347-53.

103.Zhang H, Gao C, Fang L, et al. Metformin and reduced risk of hepatocellular carcinoma in diabetic patients: a meta-analysis. Scand J Gastroenterol 2013;48:78-87.

104. Kawaguchi T, Taniguchi E, Morita Y, et al. Association of exogenous insulin or sulphonylurea treatment with an increased incidence of hepatoma in patients with hepatitis C virus infection. Liver Int 2010;30:479-86.

105. Aljada A, Mousa SA. Metformin and neoplasia: implications and indications. Pharmacol Ther 2012;133:108-15.

106.Singh S, Singh PP, Singh AG, et al. Statins are associated with a reduced risk of hepatocellular cancer: a systematic review and meta-analysis. Gastroenterology 2013;144:323-32.

107. Marrero JA, Kulik LM, Sirlin CB, et al. Diagnosis, Staging, and Management of Hepatocellular Carcinoma: 2018 Practice Guidance by the American Association for the Study of Liver Diseases. Hepatology 2018;68:723-50. 108. Hashimoto E, Tokushige K. Hepatocellular carcinoma 
in non-alcoholic steatohepatitis: Growing evidence of an epidemic? Hepatol Res 2012;42:1-14.

109.EASL, EORTC. EASL-EORTC clinical practice guidelines: management of hepatocellular carcinoma. J Hepatol 2012;56:908-43.

110. Pocha C, Kolly P, Dufour JF. Nonalcoholic Fatty Liver Disease-Related Hepatocellular Carcinoma: A Problem of Growing Magnitude. Semin Liver Dis 2015;35:304-17.

111. Kikuchi L, Oliveira CP, Alvares-da-Silva MR, et al. Hepatocellular Carcinoma Management in Nonalcoholic Fatty Liver Disease Patients: Applicability of the BCLC Staging System. Am J Clin Oncol 2016;39:428-32.

112.Piscaglia F, Svegliati-Baroni G, Barchetti A, et al. Clinical patterns of hepatocellular carcinoma in nonalcoholic fatty liver disease: A multicenter prospective study. Hepatology
2016;63:827-38.

113. Reddy SK, Steel JL, Chen HW, et al. Outcomes of curative treatment for hepatocellular cancer in nonalcoholic steatohepatitis versus hepatitis $\mathrm{C}$ and alcoholic liver disease. Hepatology 2012;55:1809-19.

114. Vigano L, Conci S, Cescon M, et al. Liver resection for hepatocellular carcinoma in patients with metabolic syndrome: A multicenter matched analysis with HCVrelated HCC. J Hepatol 2015;63:93-101.

115. Costentin CE, Mourad A, Lahmek P, et al. Hepatocellular carcinoma is diagnosed at a later stage in alcoholic patients: Results of a prospective, nationwide study. Cancer 2018;124:1964-72.

116. Naik A, Kosir R, Rozman D. Genomic aspects of NAFLD pathogenesis. Genomics 2013;102:84-95. doi: $10.21037 / \operatorname{tgh} .2019 .09 .01$

Cite this article as: Pocha $\mathrm{C}, \mathrm{Xie} \mathrm{C}$. Hepatocellular carcinoma in alcoholic and non-alcoholic fatty liver disease-one of a kind or two different enemies? Transl Gastroenterol Hepatol 2019;4:72. 